\title{
The Illusion of Exclusivity
}

Conor McHugh

\begin{abstract}
It is widely held that when you are deliberating about whether to believe some proposition $p$, only considerations relevant to the truth of $p$ can be taken into account as reasons bearing on whether to believe $p$ and motivate you accordingly. This thesis of exclusivity has significance for debates about the nature of belief, about control of belief, and about certain forms of evidentialism. In this paper I distinguish a strong and a weak version of exclusivity. I provide reason to think that strong exclusivity is an illusion and that weak exclusivity may also be an illusion. I describe a number of cases in which exclusivity seems not to hold, and I show how an illusion of exclusivity may be generated by a rather different feature of doxastic deliberation, which I call demandingness.
\end{abstract}

It is widely held that when you are deliberating about whether to believe some proposition $p$, only considerations relevant to the truth of $p$ can be taken into account as reasons bearing on whether to believe $p$ and motivate you accordingly. I am going to argue that this is, at least in part and perhaps entirely, an illusion. This has implications for several important philosophical debates.

\section{Exclusivity}

\subsection{Characterising Exclusivity}

Suppose I offer you a large reward to believe that it will rain today. Can you form the belief in order to win the reward? It has seemed to many philosophers that you cannot. More precisely, it has seemed that the prospective reward cannot play the role of a consideration that you take into account as a reason to believe that it will rain today, and that then directly motivates you, in its guise as such a reason, so to believe - that you respond to by forming that particular belief. It cannot be, in this sense, a reason for which you believe that it will rain today. I will (perhaps non-standardly) call a consideration that plays this role a 'motivating reason'. 
A motivating reason for belief is not a reason for which you form some belief, or adopt some doxastic attitude to a given proposition, but one for which you form a particular belief, or adopt the particular doxastic attitude of believing to a given proposition.

The idea, then, is that the prospect of a reward cannot be a motivating reason for belief. This has seemed to be true not only of the consideration of a prospective reward, but also of any other consideration that, by your lights, has nothing to do with the truth of the proposition to be believed.

Reflection on such examples has led many philosophers to suppose that when you deliberate about whether to believe a proposition, only considerations you take to be relevant to the truth of that proposition - i.e. evidence - can be motivating reasons for believing the proposition, reasons for which you adopt the doxastic attitude of belief to that proposition. ${ }^{1}$

This is a claim about how beliefs can be motivated from the perspective of the deliberating subject. Nobody denies that beliefs can be causally influenced by non-evidential factors. ${ }^{2}$ To give a familiar example: if it would be psychologically beneficial for me to believe that I am popular, handsome and competent, this may causally contribute to me having those beliefs. The claim is that such considerations cannot be motivating reasons, in the stipulated sense, for the beliefs. Any causal relation between the prospect of this benefit and my having the belief will not go in the normal way via the content of my deliberation, and directly to my belief (supposing I deliberate at all). ${ }^{3}$

Steglich-Petersen (2009) has labelled this apparent phenomenon 'exclusivity'. (He also uses this term for the normative claim that, roughly, only evidence can be relevant to what it is rational for you to believe. The claim I am focusing on is a psychological one.) In fact, there are two different possible phenomena in the vicinity, and accordingly there are two different exclusivity claims. The difference arises from the two ways in which deliberation about whether to believe $p$ can conclude. Such deliberation can conclude in a belief - either a belief 
that $p$ or a belief that $\sim p$. Or it can conclude in a state of withholding belief (suspending judgment). ${ }^{4}$

According to a weaker version of the exclusivity claim, non-evidential considerations cannot be motivating reasons for belief. That is, in deliberating about whether to believe $p$, you can't form the belief that $p$, or the belief that $\sim p$, even in part for a non-evidential reason. Call this the claim of weak exclusivity. ${ }^{5}$

According to a stronger version of the claim, non-evidential considerations can be motivating reasons neither for belief nor for withholding belief. In deliberating about whether to believe $p$, you can't form the belief that $p$, nor the belief that $\sim p$, nor can you conclude by withholding belief (suspending judgment) about whether $p$, even in part for a non-evidential reason. Call this the claim of strong exclusivity. ${ }^{6}$

Note that the claim of strong exclusivity does not entail that non-evidential considerations cannot be motivating reasons for avoiding forming any doxastic attitude at all to a proposition, e.g. by refusing to think about it. Withholding is not merely lacking belief and disbelief; nor is it just the state of not having made up your mind. It is, rather, a state that you arrive at when you conclude deliberation not by outright endorsing or rejecting a proposition, but by adopting a distinctive non-committed doxastic attitude to it. ${ }^{7}$

I am going to argue that strong exclusivity is an illusion and make a case that weak exclusivity is an illusion too.

\subsection{Exclusivity and Transparency}

The claims of exclusivity are closely related to the claim of transparency, which has been put to work in much-discussed papers by Shah (2003) and Shah and Velleman (2005). These authors claim that the question of whether to believe $p$ is 'transparent to' the question whether $p$, in a certain sense: 
'when asking oneself whether to believe that $p$, [one] must ... immediately recognize that this question is settled by the answer to the question whether $p$ is true[.] ... Within the perspective of first-personal doxastic deliberation, that is, deliberation about what to believe, one cannot separate the two questions' (Shah 2003: 447).

Transparency, Shah says, is a feature of the 'phenomenology of deliberation' (ibid.: 462). On asking yourself whether to believe $p$, it is immediate that you view this question in a certain way: namely, as answerable only to considerations bearing on whether $p$.

This characterisation of transparency suggests that it entails strong exclusivity: it suggests that the conclusion of deliberation about whether to believe that $p$ cannot be, within deliberation, a response to anything except evidence for and against $p$. But the claim of transparency seems to be even stronger than that of strong exclusivity. The latter claim doesn't say anything about the phenomenology of deliberation, or about how you must view the relation between the question whether to believe $p$ and the question whether $p$, immediately or otherwise. It doesn't say that you cannot view the question whether to believe $p$ as answerable to non-evidential considerations - that such considerations cannot strike you as relevant, when you ask yourself whether to believe $p$. It merely says that you can't respond directly to non-evidential considerations by forming (or withholding) the belief (as opposed to, say, by forming an intention to instil a certain doxastic state in yourself).

Thus, my argument against strong exclusivity will also constitute an argument against transparency.

\subsection{Significance: The Nature of Belief, Doxastic Control and Evidentialism}


Whether exclusivity is a genuine phenomenon, and if so whether it is so in its strong form or merely in its weak form, matters for a number of philosophical debates.

First, it matters for debates about the nature of belief. According to the teleological account of belief, it is part of the nature of belief that it has a certain aim or telos, usually taken to be truth. David Owens (2003) has pointed out that it is characteristic of aims, as ordinarily understood, to allow for a certain sort of weighing. Considerations flowing from different aims of an agent can be weighed against each other in deliberation about what to do in pursuit of those aims. Exclusivity seems to rule out this kind of weighing where pursuit of the supposed aim of belief is concerned: it rules out forming a belief even in part because doing so would contribute to some other aim of yours, besides the (supposed) aim of truth. Owens argues that this constitutes evidence against the idea that truth is an aim of belief in any explanatory sense. Owens's argument requires only the claim of weak exclusivity, since this is enough to rule out a kind of weighing that is characteristic of ordinary aims. ${ }^{8}$

Meanwhile, Shah (2003) uses the stronger claim of transparency to argue for his normativist account of belief, according to which truth is not an aim but a norm constitutive of the concept of belief. According to Shah, transparency is explained by this normativist account, but cannot be explained by the teleological account.

Secondly, the apparent unresponsiveness of our beliefs to practical reasons is often taken to show that we lack voluntary control over our beliefs. ${ }^{9}$ In achieving a more precise account of the kind and degree (if any) of control we enjoy over our doxastic states, it is relevant which, if any, version of exclusivity obtains. This is not to say, I hasten to add, that the denial of weak exclusivity would entail some substantial form of voluntarism. Even if weak exclusivity is an illusion, the role of non-evidential considerations in regulating belief is surely so limited that it would be misleading to say that the kind of control we enjoy over belief is voluntary. ${ }^{10}$ Third, exclusivity of one sort or another has been taken to support evidentialism, the view that 
only evidential considerations can be normative reasons for belief. For example, Shah (2006) argues that transparency supports evidentialism, appealing to the premise that (roughly) something can be a normative reason for belief only if it is capable of functioning as what I have called a motivating reason-a reason for which you believe. ${ }^{11}$

\section{The Illusion of Exclusivity}

\subsection{Demandingness}

I am going to offer a number of examples designed to raise doubts about exclusivity, strong and weak. In order to understand the examples and why they take the form they do, we must first consider a phenomenon that I take to be genuine and that is less frequently discussed than exclusivity. I call this phenomenon demandingness. I will be suggesting that strong and weak exclusivity are illusions generated in part by demandingness.

Demandingness is this: you cannot deliberatively form an outright belief in a proposition if you regard your evidence for that proposition as less than sufficient, where sufficiency involves more than having better or stronger evidence for the proposition than for its negation. You require what you take to be some high degree or strength of evidence, or some particular kind of evidence, for the proposition. ${ }^{12}$

For example, suppose again that you wish to form a belief about whether it will rain today. You have consulted all the available meteorological evidence, and it seems to you that the probability of rain is .6, while the probability of a dry day is .4. Can you then go ahead and conclude deliberation by forming the outright belief that it will rain? It seems not. You can believe that it will probably rain. You can increase your credence in the proposition that it will rain. But you cannot simply go ahead and believe the proposition outright, while aware that there is a .4 probability of its being false. This kind of evidence is not sufficient. 
This is not to suggest that you could not, after deliberation, end up having the belief. You could be caused to have it by some non-rational or compulsive mechanism. Or you could come to have it through self-deception or the like. What you could not do is form the belief through your ordinary deliberative control, based on evidence that you regard as merely making its content probable to degree .6. Like exclusivity, demandingness is a feature of how beliefs can be motivated from the perspective of the deliberating subject.

I am taking it here that having a credence of .6 in $p$ is not sufficient for having an outright belief in $p$. An outright belief in $p$ involves a kind of unqualified commitment, such that you will normally be prepared to use $p$ as a premise in reasoning. If you merely have a credence of .6 in $p$, you will not be prepared to use $p$ unqualified as a premise in reasoning. ${ }^{13}$

What is it for evidence to be sufficient, in the relevant sense? I have argued elsewhere that evidence for $p$ is sufficient only if you would not easily have that evidence were $p$ false, ${ }^{14}$ where 'easily' means too easily for knowledge. ${ }^{15}$ This ties in with two plausible ideas: that it is belief's 'job' to provide premises for reasoning, and that knowledge provides a standard for the use of a proposition as a premise in reasoning. ${ }^{16}$ But I cannot hope to defend this view here. What is crucial for present purposes is that there is a phenomenon of demandingness, such that your regarding a proposition as having a probability of greater than .5 is not enough to enable you to go ahead and believe it. The term 'sufficient' is in effect a placeholder for an account of the degree or kind of evidence that makes deliberative formation of belief psychologically possible.

It is important to see that demandingness and exclusivity are independent. Exclusivity rules out motivation of belief, within deliberation, by non-evidential considerations. It doesn't say anything about the strength or kind of evidence required for belief. Demandingness, on the other hand, does not entail that non-evidential considerations cannot be among the motivating reasons for belief or for withholding belief. It merely entails that, if you regard your evidence 
as insufficient, such considerations cannot effectively motivate you, through deliberation, to go ahead and believe.

There is a range of cases in which symptoms of exclusivity and symptoms of demandingness are hard to distinguish - namely, those cases in which you are considering whether to believe $p$ and you regard both your evidence for $p$ and your evidence for $\sim p$ as insufficient. In such cases, demandingness predicts that through deliberation you will be able neither to believe $p$ nor to believe $\sim p$. You will in effect be forced to withhold belief, no matter how glorious the riches you are offered to believe $p$ (or $\sim p$ ), or what other non-evidential considerations are in play. Thus, demandingness alone predicts that non-evidential considerations will be deliberatively impotent in such cases.

Philosophers interested in these matters often focus on examples in which you are offered a reward to believe some proposition for which you have insufficient or no evidence. The fact that you cannot win the reward in such examples does not provide evidence for exclusivity, because that fact is already predicted by demandingness. In order to see whether exclusivity is

genuine, we must look at cases where a subject is considering whether to believe a proposition for which the evidence is, by her lights, sufficient. It is only in these cases that the symptoms of demandingness and of exclusivity could come clearly apart. Exclusivity predicts that, even in such cases, non-evidential considerations cannot be motivating reasons for belief (weak exclusivity), or for either belief or withholding (strong exclusivity). Demandingness makes no such prediction.

\subsection{Discretion}

Before proceeding to the examples, I should make an assumption explicit. The assumption is that evidence can psychologically allow you to believe a proposition, without psychologically compelling you to believe it. That is, your take on your evidence for $p$ can be such that you 
can believe $p$, but you can also withhold belief in $p$. Many of our beliefs seem to be based on evidence of this sort. For example, in many ordinary cases in which someone offers testimony that $p$, it is possible to believe the testimony, but also both possible to withhold belief. You can raise for yourself the question whether your informant wasn't (just this once) mistaken or lying, and withhold belief until you can rule this possibility out; or, you can put such doubts aside and believe what they say. Likewise, when you have excellent inductive evidence for a proposition, it is sometimes both possible for you to believe the proposition and possible for you to withhold belief and seek further guarantees that the case in question isn't an exception to the relevant inductive generalisation. Even when you reach a conclusion by deduction, you may be able to believe the conclusion or to question whether the deduction was correctly executed and withhold belief. ${ }^{17}$

This is not to say, of course, that evidence can psychologically allow you to believe a proposition and also allow you to disbelieve it - to believe its negation.

I call this the assumption of discretion. ${ }^{18}$ This is a psychological assumption rather than a normative one. In fact I think that the corresponding normative assumption is also true. That is, your evidence can make it normatively okay or permitted to believe $p$, while also making it normatively okay or permitted to withhold belief. ${ }^{19}$ Testimonial evidence once again seems to provide some examples: often you are epistemically entitled to believe what someone tells you, without its being epistemically forbidden to withhold belief. However, it is only the psychological claim that my argument strictly requires. If the psychological assumption is mistaken, then there cannot be cases such as I will describe.

The assumption comports with my earlier suggestion that to regard evidence for $p$ as sufficient involves something like regarding it as being the case that you would not easily have that evidence were $p$ false. This allows that evidence for $p$ can be sufficient, even though you could, albeit not easily, have that evidence and yet $p$ be false. So, it will sometimes occur 
that you regard your evidence as sufficient, and yet there are possible worlds where your evidence is misleading, possible worlds that you are aware you cannot rule out. For example, the testimony of a trustworthy interlocutor might be sufficient evidence for the truth of what they say, even though you can't rule out that they are mistaken or lying. When you go ahead and believe what your interlocutor says, you are putting aside those error possibilities. You may, on the other hand, countenance those possibilities, and withhold belief. ${ }^{20}$

Note that none of this commits me to the idea that there is psychological or normative discretion over credences. ${ }^{21}$ That would follow only if your outright attitudes were fully determined by your credences. It seems to me that they are not. Even very high credences are compatible with the absence of unqualified commitment that characterises outright belief. You can have a very high credence for the proposition that the butler did it, without believing it outright. So it seems that, when your credence for a proposition is within a certain range, you sometimes have discretion over whether to make the unqualified commitment to the truth of that proposition that is constituted by outright belief. One understanding of Pyrrhonism is as the injunction to withhold this commitment wherever possible.

I am not saying that you always have discretion over whether to believe a proposition outright or not. Often your evidence for a proposition is insufficient, and you cannot believe it. Even when your evidence is (by your lights) sufficient, you may or may not have discretion over whether to believe it. It may be psychologically impossible for you not to believe it. For example, it is arguably often psychologically impossible for us not to believe what our perceptual experience presents to us as being the case in our immediate environment. My claim is merely that there are cases where you do have discretion: sometimes your evidence is sufficient by your lights, and allows for both believing and withholding of belief.

What determines whether you have discretion or not? I suggest that this is largely a matter of how remote is (by your lights) the scenario in which you would have the evidence you have 
and yet the target proposition be false. When that scenario might too easily obtain, your evidence is not sufficient, and you cannot believe. When that scenario is not possible, or when it is so remote that you cannot seriously countenance it, then you will normally be unable to withhold belief. For example, my current perceptual beliefs about my immediate surroundings could be false, given my evidence, only if I were the victim of sustained, systematic perceptual illusion or hallucination—a possibility that I cannot seriously countenance. Thus, I cannot but believe that there is a computer screen in front of me, and the rest of it. Other examples might include self-evident propositions, and propositions that transparently follow from propositions you are compelled to believe.

In the middle are cases where the error-possibility would not easily obtain, but nevertheless can be countenanced. These will be the cases in which you may have discretion. As suggested above, this will include many ordinary cases of testimony and induction, as well as, perhaps, conclusions arrived at by fallible reasoning processes.

I emphasise that I have not yet offered an argument against exclusivity. Perhaps you can enjoy discretion over whether to believe $p$, without being able to believe $p$ or not believe it for nonevidential reasons. ${ }^{22}$ In what follows, however, I will try to make plausible that when you have discretion, non-evidential considerations can play the role of motivating reasons for which you withhold belief, or for which you discount error possibilities and believe.

\subsection{Against Strong Exclusivity}

With all of these points in place, I can now try to persuade you that strong exclusivity is an illusion. My strategy will be to describe cases in which a subject ('you') regards her evidence as sufficient, but belief is not psychologically compelled, and in which a false belief would be undesirable. I will invite you to judge that the subject could withhold belief for a nonevidential reason, and I will argue against various sources of resistance that you may have to 
accepting this.

I recognise that this sort of judgment about what a subject could do in an imaginary case cannot be decisive. My aim is not to decisively refute exclusivity, but only to shift the ground against it. Note that arguments in favour of exclusivity have typically taken the form of cases about which the reader is invited to judge that the protagonist would be unable to form some evidentially unsupported belief, and then to extrapolate from this a general principle of exclusivity (strong or weak). While trading in examples can only take us so far, I want to suggest that the debate until now has erred in focusing on examples where exclusivity and demandingness cannot be separated, and that when we focus on cases where they can be separated, we find that there is reason to reject strong (and weak) exclusivity.

Here are two cases.

A. Your friend is accused of some terrible wrong, and several seemingly independent witnesses have reported that he did it. By your lights, you would not easily have this evidence were your friend not guilty. It would require that all of witnesses be either mistaken or lying - a possibility that cannot strictly be ruled out, but is far-fetched. However, you value the friendship and you think that, if you were to believe in your friend's guilt, it would have profoundly damaging effects on the friendship, particularly should your friend turn out to be innocent after all.

In this scenario, you cannot clear-headedly believe that your friend is not guilty. But it seems that, in deliberating about whether to believe that your friend is guilty, you can take into account a non-evidential consideration, namely the potential damage of believing that your friend is guilty, and you can conclude deliberation by withholding belief, remaining open to the possibility that the witnesses are mistaken or lying, for this reason. ${ }^{23}$ 
B. You have a cheque that you badly need to lodge by the end of the week. ${ }^{24}$ It would be much easier to lodge it tomorrow (Saturday) than today (Friday). You have been to the bank on Saturdays before, and thus have what you regard as sufficient inductive grounds to believe that the bank will be open tomorrow. However, it is not impossible that the bank has changed its hours.

Ordinarily, you would believe, on the basis of such inductive grounds, that the bank will be open tomorrow, putting aside the possibility of a change in hours. In this situation, however, it is very important that you not be wrong about whether the bank will be open tomorrow. It seems that you can, for this reason, withhold belief on the matter, taking seriously the possibility of a change in hours.

Note that, in each case, the relevant practical consideration is one that favours adopting a particular doxastic attitude - that of withholding, or suspended judgment - to the target proposition, a doxastic attitude that you can conclude deliberation by adopting. It does not favour merely lacking belief or disbelief.

I am not suggesting that you are always guaranteed to succeed when you try to withhold a belief in this way. You might find yourself stubbornly convinced of the truth of $p$, despite wishing to withhold belief and countenance error possibilities. My claim is only that you can sometimes withhold beliefs in the way described. Non-evidential considerations are not excluded from being motivating reasons for withholding belief.

If I am right that even one such case is possible, then there is no such thing as strong exclusivity.

It might be objected that, in so far as such cases are possible, you do not really withhold belief in the target proposition, but rather decide, in light of the stakes, not to act on a belief that you 
in fact hold. Thus, though you believe your friend to be guilty, you refrain from saying so, or from otherwise acting on the belief, in order to preserve your friendship. Though you believe that the bank will be open tomorrow, you check anyway.

Of course it can happen that in certain circumstances you refrain from acting on a belief you in fact hold. But that doesn't seem to be always the right description of these sorts of cases. In the first case, after all, your concern is ex hypothesi with the belief itself, not primarily with how you act; it is believing in your friend's guilt that you regard as undesirable. And your act of solidarity is to refuse to believe it. This is importantly different from refusing to act on your belief that he is guilty, and it seems that such acts of solidarity are sometimes possible. In the second case, it seems that it would be, at best, quite unusual for you to believe outright that the bank will be open even while you are going to serious lengths to check whether it will be open, while you are (as we might suppose) disposed to say you don't know whether it's open, and so on.

A second objection would be that, in so far as such cases are possible, they are not cases of withholding a belief for some motivating reason, but rather of your being unable to bring yourself to believe the target proposition. Thus, there is no motivating reason for which you withhold belief; it is a brute failure to believe.

Again, this is surely something that can happen, but it doesn't seem always to be what is going on. It might happen that you can't bring yourself to believe in your friend's guilt; it might happen that you refuse to. And it would take very unusual circumstances for the bank's being open tomorrow to be a prospect you find so distressing as to be unable to bring yourself to believe it.

A third objection is that, in such cases, practical considerations do not function as motivating reasons for which you withhold belief, but rather they function to modify the contextually fixed standards for what counts as sufficient evidence. ${ }^{25}$ For example, they help to fix how 
easily a proposition's being false despite your evidence counts as easily, such that the evidence is not sufficient. When the practical stakes are high for you, standards are higher, so you need stronger evidential reasons than you otherwise would to have sufficient evidence for the belief, and thus you need stronger evidential reasons to be motivated to believe. But your motivating reasons for withholding belief will be purely evidential.

Let me allow for the sake of argument that practical considerations can make a difference to what counts as sufficient evidence. That would not show that such considerations cannot be motivating reasons for which you withhold belief. Indeed, if a practical consideration plays the role of raising your standard for sufficient evidence, then that would seem to make it a good candidate for a reason for which you would withhold belief. Thus, if this objection is to pose a problem for my argument, it must be supposed that a practical consideration can raise your standard for sufficient evidence, but cannot be a reason for which you withhold belief. Thus, a practical consideration can influence you to withhold belief, or to lose a belief you previously held, without being a reason for which you do so, and even though there is no change in your evidence. You cannot deliberatively acknowledge the role of the practical consideration in such events of doxastic rearrangement, and yet there is no change in your evidence that could explain them either. It thus becomes puzzling what would be going on from your own point of view, in such a case.

In any case, I stipulated in the examples above that you regard your evidence for the target proposition as sufficient. ${ }^{26}$ So, if you withhold belief, that will not be because the stakes have raised the standard of sufficiency to a level that your evidence fails to meet. It seems to me that issues of contextual variability are orthogonal to my argument. The question whether non-evidential considerations can come into play as motivating reasons for withholding belief, given some standard of sufficiency, is independent of the question whether that standard is contextually fixed or not. 
So I think it's hard to deny that cases of the sort I described are at least possible.

\subsection{Against Weak Exclusivity}

I now describe cases to put pressure on weak exclusivity. These are cases in which it seems that the desirability of having a belief can be part of what motivates you to put aside farfetched error possibilities and believe a proposition-provided, of course, that the evidence for the proposition is, by your lights, sufficient. My conclusion regarding weak exclusivity is more tentative than that regarding strong exclusivity because I think there is some room for treating the examples to follow in a way that is compatible with weak exclusivity. I will argue, however, that they are naturally regarded as providing evidence against weak exclusivity, and we are entitled to regard them as such in the absence of some argument to the contrary. Thus, I will place the burden on the defender of weak exclusivity to provide a principled argument that it is a genuine phenomenon. ${ }^{27}$

Here are three such cases.

C. Your friend is accused of some terrible wrong, but he has an alibi supported by several seemingly independent witnesses. By your lights, you would not easily have this evidence were your friend not innocent. It would require that all of the witnesses be either mistaken or lying - a possibility that cannot strictly be ruled out, but is far-fetched. What's more, you value the friendship and you think that, if you did not believe in your friend's innocence, it would have profoundly damaging effects on the friendship, should he indeed turn out to be innocent.

In this scenario, you could withhold belief about whether your friend is innocent, and await further evidence - after all, for all the evidence you have, he might not be innocent. However, 
it seems that, in deliberating about whether to believe that your friend is innocent, you can take into account a non-evidential consideration, namely the good of believing that your friend is innocent, and form the belief, putting aside the far-fetched possibility that the witnesses are mistaken or lying. ${ }^{28}$

D. You are playing tennis. You are much stronger than your opponent, so you regard the possibility of defeat as far-fetched. If you believed that you would win, your confidence would make victory even more likely.

Here, you could withhold judgment about whether you will win-after all, upsets happen, and there's nothing to rule out the possibility that this match will be an upset. But it seems that, in deliberating about whether to believe, given your (by your lights sufficient) evidence, that you will win, you can take into account the consideration that believing it will promote one of your goals (that of winning), and form the belief, putting aside the far-fetched possibility of an upset.

E. You are a car salesman. You are trying to sell a particular car. All the evidence suggests that it is reliable - the model is said to be very reliable, and there is nothing to suggest that this particular vehicle is any exception, but you can't absolutely rule out that there is some fault somewhere. You will be more convincing in your sales pitch if you believe that the car is reliable. ${ }^{29}$

Again, it seems that you could withhold belief until certain far-fetched possibilities were ruled out; you might do this if you were considering buying the car yourself. But as it happens you have reasons not to be unduly cautious. It seems that, in deliberating about whether to believe, 
given your evidence, that the car is reliable, you can take into account the non-evidential reason to form that belief, and form it, putting aside far-fetched error possibilities.

To emphasise: I am not suggesting that in these cases you can form the target belief simply because it would be beneficial in a certain way to have that belief. I am suggesting that, given that you have what you regard as sufficient evidence for a proposition, non-evidential reasons can be among the motivating reasons for which you go ahead and believe on the basis of that evidence.

Nor am I suggesting that you are always guaranteed to succeed when you try to form a belief in this way. You might find yourself somehow unable to bring yourself to believe $p$, even though you regard your evidence as sufficient and wish to believe it. The suggestion is only that you can sometimes form beliefs in the way described. Non-evidential considerations are not excluded from being motivating reasons for belief.

If I am right that even one such case is possible, there is no such phenomenon as weak exclusivity.

It might be objected that, in the sorts of cases I describe, you can't directly form the target belief for the cited non-evidential reason. Rather, you can first do something else-for example, you can attend to a subset of the evidence-in order to affect your view of the evidence, so that you may then be able to form the belief directly on the basis of the evidence and nothing else. So, non-evidential considerations cannot really play the role of (directly) motivating reasons for belief.

This objection construes the cases I have described as being similar to cases in which you get yourself to believe a proposition that you want to believe (say, that there is a god), by first manipulating yourself into regarding your evidence as supporting the proposition. This sort of strategy is notoriously problematic. It requires self-deception: in the course of the manipulation you must somehow ignore or forget the fact that you are intentionally 
manipulating your view of the evidence, so that you can really arrive at the view you want. For this reason, the strategy is not reliably successful. ${ }^{30}$

You do not need to engage in such a tortuous and self-deceiving process in order to instill in yourself the belief that your friend is innocent, that you will win the tennis match, or that the car is reliable. Furthermore, it's unclear what such self-manipulation could be aiming to achieve. In classic cases of self-deception, such as Pascal's wager, you initially regard the evidence as insufficient, and so you need to do things indirectly-you need to pass through a stage of changing your view of the evidence, before you can form the desired belief. In my examples, by contrast, you already have what is, by your lights, sufficient evidence for the target proposition. There is thus no task of changing your view of the evidence. There is nothing indirect to be done-no intermediate stage to go through, before you can form the belief. So it looks like, if you can come to form the belief partly in response to a practical consideration, you can do so directly.

It might be said that, even if you can come to form the belief directly because of a practical consideration, you cannot do so in response to such a consideration. Your awareness in deliberation of the desirability of believing that your friend is innocent might cause you to have that belief, but this consideration cannot be a reason for which you form the belief. The causal chain between your awareness of the practical consideration and your forming of the belief will be deviant.

I do not know how to refute this suggestion. However, I think it is prima facie implausible. Typical examples of deviant causal chains involve some highly indirect and coincidental route between cause and effect. For example, it strikes you as desirable to believe that your friend is innocent, and your impassioned reflection on the matter causes an aneurysm which rewires your brain in such a way that you now believe that your friend is innocent. I don't deny that this could happen. But it seems to me that you can come to believe that your friend is 
innocent without any such bizarre series of events. You appreciate a (putative) reason for forming the belief, and come to form the belief directly because of your awareness of that reason, and because of your appreciation of its probative force, without any coincidences or unusual interventions. This looks very much like doing something for a reason. Likewise for the other examples. If deviant causal chains were required for such cases to occur, they would be much more bizarre than they in fact seem to be. So I think that, in the absence of an argument to the contrary, the suggestion that these can only be cases of deviant causal chains can be dismissed as implausible.

Another objection would be that, insofar as the cases I described are possible, they involve deliberation that fixes not the attitude of belief, but some other propositional attitude. The obvious suggestion is that they involve some form of acceptance that is distinct from belief. ${ }^{31}$ While you might, in such a case, only manage some form of acceptance that does not amount to belief, it's far from clear that this must be so. In the imagined examples, the attitude you deliberate over is one that aims at truth, that is regulated by evidence, and that guides behaviour in the way characteristic of belief. It is not an acceptance that is bound to a particular context. And it seems that you can, as a result of such deliberation, adopt or withhold an attitude that has these characteristics. It therefore looks very much like a belief.

I do not claim to show that such cases cannot be treated as cases of acceptance rather than belief, or in some other alternative way. But since they seem to bear marks distinctively characteristic of belief, any such alternative treatment would need to be accompanied by an argument in its favour. My aim, to repeat, is to place the burden of proof on the defender of weak exclusivity.

One such argument would appeal to the following claim: in the cases I described, you could not justify the target belief by appeal to the non-evidential consideration that supposedly partly motivated it. For example, if asked to justify your belief that your friend is innocent, 
you could not legitimately reply by citing the value of trust in a friendship. Indeed, it might be added, non-evidential considerations can never be cited as (even partial) justifications for beliefs. But a motivating reason for doing or believing something is precisely the sort of thing that (when it is a good reason, at any rate) you can appeal to as a justification for doing or believing it. So, non-evidential considerations cannot be motivating reasons for belief. ${ }^{32}$

There is a sense of the term 'justification' that is purely epistemic. It is true that non-evidential considerations can't be cited in the justification in this sense of a belief. But this doesn't show that such considerations can't be among the motivating reasons for belief, unless it is also assumed that the motivating reasons for belief must be epistemic reasons. In the present context, such an assumption would be question-begging.

So, the notion of justification at work in the argument must apply to any consideration that can legitimately be cited in support of one's having a belief. And the claim must then be that, in fact, only epistemic, and hence evidential, considerations can legitimately be so cited.

My reply to this is that non-evidential considerations can legitimately be cited as justifications for beliefs, in the sense of justification relevant to this argument. They are only very partial justifications: to show that you are justified in holding a belief you must also show that you have sufficient evidence for it. ${ }^{33}$ And they are non-epistemic justifications. But they are justifications nonetheless.

Suppose, for each of my examples, that you are challenged to justify your belief. Now, a challenge to justify a belief is very often meant to be understood as a demand for evidence; this is connected to the epistemic sense of 'justification', and to the fact that the person issuing such a challenge is very often interested primarily in the question whether the proposition you believe is true. But a challenge to justify a belief might also be simply a challenge to show that you are reasonable in having the belief. Imagine, for example, that the person issuing the challenge already knows very well whether the proposition you believe is true, and is trying to 
establish something about your reasonability instead. Suppose that it is accepted on all sides that you have sufficient evidence for your belief, but that your interlocutor challenges you to justify your going ahead and forming the belief, rather than remaining cautiously agnostic. When challenged in this way, it can be legitimate to say things like, 'I don't doubt his innocence because he's my friend, and trust is important in a friendship', or, 'Believing that I will win, rather than nurturing doubts, helps me play better', or, 'If I don't believe the car is reliable it will be harder to sell it'. In the right context, these kinds of responses can be legitimate.

I admit that there is something initially plausible about the thought that the only thing you can cite to justify a belief is evidence. But I think this impression is explained away by the points made above about the term 'justification', about the partialness of non-evidential justification, and about the context in which a demand for justification is usually made.

Thus, this argument against treating the examples as cases of belief-formation partly for practical reasons fails. Although the defender of weak exclusivity can treat the examples in alternative ways, consistent with weak exclusivity, we have seen no positive argument for doing so, and some reason not to. In view of this, I conclude that we have some reason to deny there is such a phenomenon as weak exclusivity. Those who think there is such a phenomenon owe us a principled argument for believing in it. I do not claim to have shown that no such argument can be made, but only to have placed the burden on the defender of weak exclusivity to make it.

\subsection{Explaining the Illusion}

I think exclusivity is an appearance generated by demandingness. Recall that demandingness predicts that, in cases where the evidence for a proposition $p$ is insufficient by your lights, you will be unable (without self-deception or the like) to bring yourself to believe $p$-no matter 
what non-evidential considerations might favour believing $p$. Now, if we as theorists are wondering whether non-evidential considerations can be motivating reasons in deliberation that fixes belief, we will be inclined to look precisely at cases in which the evidence does not favour, or is only weakly in favour of, the target proposition. For these would be cases in which, other things equal, any role being played by non-evidential considerations would come through most clearly. So, the cases we are inclined to look at to assess whether exclusivity is a genuine phenomenon will be cases in which non-evidential factors are indeed impotent within deliberation that fixes belief. Thus, a pattern that is in fact generated by demandingness will give us the impression of exclusivity. This misleading impression is exacerbated by our failure to see the possibility of an alternative explanation for the data. ${ }^{34}$

Besides all this, when you deliberate about what to believe, your dominant concern typically $i s$ to get at the truth, and so it is on truth-relevant considerations that you focus. This may well contribute to the impression that non-evidential considerations cannot play a role in such deliberation.

No wonder, then, that the claims of strong and especially of weak exclusivity seem so plausible to us. If what I have argued is right, this impression, while understandable, is misleading.

\section{Conclusion}

I have argued that the claim of strong exclusivity is false. If that's right, then the yet stronger claim of transparency, recently so influential, is also false.

This would undermine Shah's argument for normativism about belief, to which the claim of transparency is essential. Indeed, if Shah is right that normativism entails transparency, ${ }^{35}$ then the falsity of transparency would show that normativism is false.

This would also show that certain versions of anti-voluntarism about the control of belief are 
false.

I have also argued that we should not accept the claim of weak exclusivity, in the absence of some successful positive argument for it. If that's right, then one objection to teleological accounts of belief is disarmed. Pace Owens, we would have no reason to accept that the regulation of belief cannot be like ordinary, aim-directed behaviour, in which considerations flowing from different aims are weighed against each other. ${ }^{36}$

Certain further versions of anti-voluntarism are also thrown into question, and a seemingly powerful argument for evidentialism is blocked. Note that this argument for evidentialism could not be recast with the claim of demandingness in place of weak exclusivity: if beliefs can sometimes be (in part) responses to practical considerations, even if only in the presence of sufficient evidence, then the principle that normative reasons must be capable of functioning as motivating reasons simply does not yield the conclusion that practical considerations cannot be normative reasons for belief.

An important lesson of this paper, I think, is that the relatively neglected phenomenon of demandingness is more important than has generally been appreciated. Demandingness deserves attention, both as an interesting phenomenon in need of explanation, and for what it might tell us about the nature of belief, doxastic control and epistemic normativity. ${ }^{37,} 38$

\section{References}

Adler, J.E. (2002), Belief's Own Ethics. Cambridge, MA: MIT Press.

Alston, W.P. (1988), 'The Deontological Conception of Epistemic Justification', Philosophical Perspectives, 2: 257-299

Bennett, J. (1991), 'Why Is Belief Involuntary?', Analysis, 50: 87-107.

Bird, A. (2007), 'Justified Judging', Philosophy and Phenomenological Research, 74: 81-110.

Bratman, M. (1992), 'Practical Reasoning and Acceptance in a Context', Mind, 101: 1-15. 
Cohen, L.J. (1992), An Essay on Belief and Acceptance. Oxford: Clarendon.

De Rose, K. (1992), 'Contextualism and Knowledge Attributions', Philosophy and Phenomenological Research, 52: 913-29.

Dretske, F. (1971), 'Conclusive Reasons', Australasian Journal of Philosophy, 49: 1-22.

Frankish, K. (2007), 'Deciding to Believe Again', Mind, 116: 523-47.

---(2009). 'Partial Belief and Flat-Out Belief', in F. Huber and C. Schmidt-Petri (eds.) Degrees of Belief. Dordrecht: Springer.

Friedman, J. (forthcoming), 'Suspended Judgment', Philosophical Studies.

Ginet, C. (2001), 'Deciding to Believe', in M. Steup (ed.) Knowledge, Truth, and Duty: Essays on Epistemic Justification, Responsibility and Virtue. Oxford: OUP.

Hawthorne, J. (2004), Knowledge and Lotteries. Oxford: Clarendon.

Hieronymi, P. (2008), 'Responsibility for believing', Synthese, 151: 353-73.

---(2009). 'Two Kinds of Agency', in L. O'Brien and M. Soteriou (eds.) Mental Actions. Oxford: OUP.

Kelly, T. (2002), 'The Rationality of Belief and Some Other Propositional Attitudes', Journal of Philosophical Research, 110: 163-96.

McHugh, C. (2011a), 'Judging as a Non-Voluntary Action', Philosophical Studies, 152: 24569.

---(2011b), 'What Do We Aim At When We Believe?', dialectica, 65: 369-92.

---(forthcoming a), 'Belief and Aims', Philosophical Studies.

---(forthcoming b), 'Epistemic Deontology and Voluntariness', Erkenntnis.

---(forthcoming c), 'Exercising Doxastic Freedom', Philosophy and Phenomenological Research.

---(under review), 'Normativism and Doxastic Deliberation'.

Nagel, J. (2010), 'Epistemic Anxiety and Adaptive Invariantism', Philosophical Perspectives, 
24: 407-35.

Nelson, M.T. (2010), ‘We Have No Positive Epistemic Duties’, Mind, 119: 83-102.

Nickel, P. (2010), 'Voluntary Belief on a Reasonable Basis', Philosophy and Phenomenological Research, 81: 312-34.

Owens, D. (2000), Reason Without Freedom: The Problem of Epistemic Normativity. London: Routledge.

---(2003), 'Does Belief Have an Aim?', Philosophical Studies, 115: 283-305.

Shah, N. (2003), 'How Truth Governs Belief', Philosophical Review, 112: 447-82.

---(2006), ‘A New Argument for Evidentialism', The Philosophical Quarterly, 56: 481-98.

Shah, N. and Velleman, D. (2005), 'Doxastic Deliberation', The Philosophical Review, 114: 497-534.

Stanley, J. (2005), Knowledge and Practical Interests. Oxford: OUP.

Steglich-Petersen, A. (2006), 'No Norm Needed: On the Aim of Belief', The Philosophical Quarterly, 56: 499-516.

---(2008), 'Does Doxastic Transparency Support Evidentialism?', dialectica, 62: 541-7.

---(2009), 'Weighing the Aim of Belief', Philosophical Studies, 145: 395-405.

Stroud, S. (2006), 'Epistemic Partiality in Friendship', Ethics, 116: 498-524.

Velleman, J.D. (2000), 'On the Aim of Belief', in his The Possibility of Practical Reason. Oxford: OUP.

Walker, M.T. (1996), ‘The Voluntariness of Judgement', Inquiry, 39: 97-119.

---(2001), 'Williams, Truth-Aimedness and the Voluntariness of Judgement', Ratio, 14: 6883.

White, R. (2005), 'Epistemic Permissiveness', Philosophical Perspectives, 19: 445-59.

Williams, B. (1973), 'Deciding to Believe', in his Problems of the Self. Cambridge: CUP.

Williamson, T. (2000), Knowledge and its Limits. Oxford: OUP. 


\title{
Conor McHugh
}

\author{
Philosophy
}

University of Southampton

Southampton SO17 1BF.

\author{
C.McHugh@soton.ac.uk
}

I use 'evidence' to refer to any consideration that bears on the truth of a proposition. The notion of
bearing on the truth of a proposition I will leave intuitive.
2 As emphasised by Shah (2003).
3 This consideration could perhaps motivate me, through deliberation, to take measures to instil in myself
the belief that I am popular, handsome and competent. But then the motivation will not be direct.
4 Here, as throughout except where otherwise indicated, I am focusing on outright attitudes rather than
credences.
5 This claim seems to be endorsed by Bennett (1991), Walker $(1996,2001)$, Owens $(2000,2003)$, Kelly (2002) and Hieronymi (2008). Something like this claim is assumed or suggested in many other works.

6 This claim seems to be endorsed by Shah (2003), Shah and Velleman (2005) and Steglich-Petersen (2008). Some of the authors cited above as supporting weak exclusivity seem also at times to flirt with strong exclusivity.

There is a third position in logical space: one could hold that withholdings can be motivated only by evidence, but that beliefs can be motivated by non-evidential considerations. To my knowledge nobody has ever defended this position, and it is hard to see why anyone would. I leave it aside.

$7 \quad$ See Friedman (forthcoming) for discussion.

8 Owens's argument is discussed and rejected in Steglich-Petersen (2009). In McHugh (forthcoming a) I argue that Steglich-Petersen's defence of the teleological account fails. The present paper offers an alternative defence. forthcoming c).

10 See McHugh (2011a, forthcoming b, forthcoming c). Here I am at terminological odds with Frankish (2007).

11 See also Kelly (2002), and see Steglich-Petersen (2008) for discussion.

12 See McHugh (2011b: 376ff.). Something like this feature is also pointed out by Owens (2000, 2003), Adler (2002), and Nickel (2010); Adler and Nickel use the term 'adequate' rather than 'sufficient'.

13 See Williamson (2000: 98-99); Frankish (2009).

14 Compare Dretske (1971) on 'conclusive reasons'.

15 See McHugh (2011b). Contrast Nickel (2010), who says that evidence is 'adequate' when it implies or is reliably correlated with the truth of a proposition, assuming normal background conditions. This is compatible with there being an open question about whether normal background conditions obtain. Nickel claims that belief can be both rationally permissible and possible when the evidence is adequate in this sense.

16 Compare Bird (2007).

17 See Nickel (2010) and Nagel (2010) for similar assumptions. Note that this assumption does not commit me to voluntarism about belief, for the same reasons that the denial of exclusivity, a stronger claim, does not commit me to voluntarism (see sec. 1.3 above).

18 I borrow the term 'discretion' from Pamela Hieronymi (2009). I do not claim to be using it in the same way as she does.

19 This normative claim is defended by Nickel (2010) and by Nelson (2010).

20 The existence of such a range of cases is also defended by Frankish (2007), by Ginet (2001) and in 
McHugh (2011a).

21 See White (2005) for discussion and for some arguments against the claim of normative discretion about credences.

22 This appears to be Owens's view in (Owens 2000), and may be Nickel's view (Nickel 2010). A Pyrrhonian might also endorse this, in so far as the reasons she offers for withholding outright belief are broadly evidential.

${ }_{23} \quad$ Compare Stroud's discussion of 'epistemic partiality' in friendship (Stroud 2006).

24 This case is of course an adaptation of the famous 'bank' case described by De Rose (1992). The 'bank' case, and other similar cases, are supposed to support pragmatic encroachment on knowledge by eliciting varying intuitions about whether a subject knows a proposition, depending on some pragmatic variable, such as the stakes. I think that one factor behind such intuitions is that, imagining ourselves as the protagonist in the 'high stakes' versions of the cases, we judge that we would and could refrain from forming the target belief. Thus, I think many of these cases could be used to support my argument here.

25 This objection would appeal to a version of subject-sensitive invariantism (Hawthorne 2004; Stanley 2007). Thanks to an anonymous referee here.

26 If subject-sensitive invariantism is true, this means that in the examples you regard your evidence as very good indeed, since weighty practical concerns are in play. We could fill out the examples accordingly. The present point is unaffected: however good your evidence is, if it falls short of psychologically compelling belief, there will be room for you to be cautious and withhold outright belief (as the Pyrrhonian would urge).

$27 \quad$ Existing arguments against doxastic voluntarism target the idea that you could form a belief entirely for practical reasons, without regard for the evidence (e.g. Williams 1973; Adler 2002). To show that this is impossible is not yet to defend weak exclusivity. Frankish (2007) makes a similar point.

28 Again, compare Stroud (2006).

29 This case is adapted from one of Nickel (2010), who makes a somewhat different point.

30 Perhaps not all cases of self-deception are so problematic. Sometimes the desirability of believing something can help to causally bring about your believing that thing in an epistemically irrational way. But note that what is being envisaged is intentional self-deception: recognising some respect in which holding a belief would be desirable, and intentionally taking measures to instil that belief in yourself. This is the form of selfdeception which is problematic - to the extent that some have doubted its possibility.

31 On acceptance, see Bratman (1992), Cohen (1992) and Velleman (2000).

32 Thanks to Tony Booth and Daniel Whiting for suggesting this.

One could also claim that non-evidential considerations can never legitimately be cited as (even partial) justifications for withholding belief. On this basis one could mount a defence of strong exclusivity. But this claim is surely false. The importance of getting things right can legitimately be cited as a reason for withholding belief until more evidence comes in.

33 Frankish (2007) also claims, in reply to a similar objection, that non-evidential considerations can never be sufficient to show a belief to be justified. I think this reply alone is not successful, in so far as the argument is based on the claim that non-evidential considerations cannot be cited as even partial justifications of belief, rather than the claim that they cannot be cited as sufficient justifications.

$34 \quad$ Frankish (2007) also claims that we are misled into believing in (what I call) weak exclusivity because we confound it with something like demandingness. See also McHugh (forthcoming a).

35 However, see Steglich-Petersen (2006) and McHugh (under review) for doubts about this.

$36 \quad$ See McHugh (forthcoming a).

37 See McHugh (2011b, forthcoming a) for discussion of some of this.

38 Thanks to Daniel Whiting, Jonathan Way, Tony Booth, Asbjørn Steglich-Petersen, Joëlle Proust, Kirk Michaelian, Claudine Tiercelin, Ema Sullivan-Bissett, Nate Sharadin, an audience at the University of Århus, and several anonymous referees. The preparation of this article was supported by l'Agence Nationale de la Recherche, under the contract ANR-08.BLAN-0205-01. 